\title{
Mastery Learning improves Nursing Students' skills The implementation of Mastery Learning method
}

Roghayeh Mehdipour Rabori

Kerman University of Medical Sciences

Monirsadat Nematollahi ( $\nabla$ m.nematolahi@kmu.ac.ir)

Kerman University of Medical Sciences https://orcid.org/0000-0002-0905-8802

Behnaz Bagheryan

Kerman University of Medical Sciences

Research article

Keywords: Clinical education, Nursing Students, Mastery Learning method, nursing skills

Posted Date: July 10th, 2019

DOI: https://doi.org/10.21203/rs.2.11229/v1

License: (1) This work is licensed under a Creative Commons Attribution 4.0 International License.

Read Full License 


\section{Abstract}

Abstract Background and purpose: Clinical education is an important part of nursing education and it is influenced by teaching methods. On the other hand, educational methods play an important role in shaping students' basic skills and professional abilities. In order to promote clinical skills in students, the use of new clinical teaching methods seems necessary. Nevertheless, a lot of nursing instructors in Iran use traditional methods to teach nursing skills to the undergraduate nursing students in hospitals. In this interventional study, we compared the effect of mastery learning method and common learning method on the performance of undergraduate nursing students between 2106-2018. method After receiving written consent, the participants were randomly divided into two groups of intervention and control. Participants' performance in five common intensive care unit (ICU) procedures (i.e. trachea and tracheostomy suction, nasogastric tube feeding, packed cell transfusion, changing set and fluid box, and changing fluid box) was assessed before and after the intervention. The assessment of participants was done by a researcher- made checklist. Data were analyzed using SPSS (version 21). findings: No significant difference in terms of procedures performance was observed between two groups before the intervention ( $p>0.05)$. However, paired $t$ test showed that the scores of the intervention group before and after intervention were significantly different $(p<0.05)$. Conclusion: This study revealed that the implementation of mastery learning method in clinical skills training could be very effective in improving the quality of clinical learning of nursing students.

\section{Summary Of Relevance}

Problem or Issue: The use of new clinical teaching methods seems necessary; however, a lot of nursing instructors in Iran use common learning methods to teach nursing skills to the undergraduate nursing students in hospitals. Applying common learning methods reduced the quality of clinical education in nursing.

What is already known: In order to promote clinical skills in students, the use of new clinical teaching methods seems necessary.

What this paper adds: The implementation of mastery learning method for teaching clinical skills can improve the quality of clinical learning of nursing students.

\section{Background}

Clinical education is an important part of nursing and midwifery education (1). The purpose of clinical education is to teach students how to use clinical skills correctly.

At the moment, all efforts are being made to create conditions where clinical education can lead to students' skills, and contribute students to learn professional behaviors, provide care services on the basis of their professional activities, and respond appropriately to specific clinical situations (2). The importance of clinical education in personal and professional development is undeniable and clinical 
education is the base of nursing education (3). Previous studies have indicated a relatively deep gap in the educational process of nursing and midwifery and the clinical practice of students, so that existing clinical education does not provide the student with the ability to express the proficiency and clinical skills (4). Through enhancing the quality of clinical education, we will have more skilled nurses and consequently more healthy community (4-6). The role of nursing faculties is to equip nurses with enough knowledge and clinical skills to meet the needs of patients and provide clinical services based on scientific advancements (7). Clinical education is a complex process that is influenced by many factors and variables (8). The clinical environment encompasses all the conditions and impacts that affect learning, provides conditions for learning, and simultaneously acts as a factor in learning or restricting learning situations (9). In Iran, current clinical education does not provide the student with the ability to attain a degree of clinical competence.

Nursing students are supposed to combine knowledge from nursing, biological, and social sciences in order to be able to make clinical decisions and provide care in different clinical settings (9). Knowing how to use educational methods in clinical practice and how to evaluate students' performance is a challenge in nursing education. (5). Achieving proper productivity requires equipping the instructors by the necessary skills (6).

Due to numerous problems such as improper practice performance of graduates in implementing clinical procedures, unavailability of a skilled trainer for students (10) and, in some cases, lack of collaboration between departmental staff and clinical students and educators for clinical education (11), changes and reforms in clinical education seems essential. One of the way to improve level of education is using effective methods for clinical education.

Mastery learning method is one of the suggested approaches to enhance educational quality. This method is based on Carroll's beliefs, suggesting that if sufficient time is given to the full extent of learning, a good level of learning can be achieved (12). Mastery learning method has a great deal of proficiency in terms of mastery. Although this method creates anxiety in the student due to frequent evaluations and it is time consuming, mastery learning method help students use the clinical skills correctly and fulfill professional responsibilities in the future (13). Wayne et.al, found that the mastery learning method was really influential in performing cardio pulmonary resuscitation skills in medical students (14).

A previous study showed that this method made students more active, and suggested this method as one of the best ways to achieve professional skills (15). Our participants achieved a good level in skills by this method. This is one of the most important benefits of this method. Today, a large number of medical educators are looking for ways to provide ideal skill training. In clinical setting, many instructors use common learning methods. Considering the needs of the clinical environment for having skilled and experienced staff, routine clinical education should be modified to adapt to the advances and technologies developed in hospitals and medical centers and to meet the complex needs of the patients 
and the clinical environment. The method of mastering learning is a new applied method for training students in medical sciences, and it is one of the individual learning styles (16).

In Iran, the instructors usually apply traditional methods for teaching clinical skills in hospitals. One of the main challenges is the unawareness of the instructors about new approaches in teaching clinical skills. Further, there are limitations in studies that examined the impact of mastery learning method on clinical students' skills. Time consumption in implementation and evaluation of this method caused the instructors do not use it for teaching clinical skills.

Therefore, we compared the effect of mastery learning method and traditional method on the performance of nursing students in Intensive Care Unit. The results of this study can contribute clinical educators to select the most beneficial teaching method.

\section{Methods}

This semi experimental study was conducted in Kerman, Iran, between 2016-2018. Kerman has two Nursing and Midwifery Faculties, one affiliated to the University of Medical Sciences and the other to Islamic Azad University.

The participants of this study consist of 100 nursing students were recruited for the current investigation, according to inclusion criteria. The inclusion criteria were being nursing student of 7 th or 8 th semester and do not undergo this educational method previously.

Data were collected by a checklist which consisted of two sections. The first section was allocated to participants' demographic characteristics, namely age, sex. The second section related to common procedures in ICU. Each procedure was scored by the same observer using three scales of done correctly (score 1), done incorrectly (score 0), and not done (score 0 ). Then, each student's scores for skill performance were calculated. In order to achieve validity, the checklist was checked for quality of content. In addition, the reliability of checklist was estimated $(a=0 / 85)$.

The participants were randomly divided into two groups of control and intervention. Participants in control group $(n=50)$ exposed to common learning method of education, and those in the intervention group $(n=50)$ underwent mastery learning method.

In order to achieve reliable data, similar educational content and materials, equal number of participants in each group, equal internship length, and the same instructor were regarded.

In addition, one-blind method was used to reduce bias in research results and the participants were not informed about the educational method.

After obtaining written consent, the participants were randomly divided to two groups of control and intervention. In the first day, the instructor assessed five common procedures in intensive care unit (ICU), namely trachea and tracheostomy suction, nasogastric tube feeding, packed cell transfusion, changing 
set and fluid box, and changing fluid box and scored each participants using a checklist available. The assessment provided students with feedback to identify what they had learned to that point (diagnostic feedback) and what they needed to learn better (prescriptive feedback).

In the control group, the instructor first explained the stages of each skill and then practically performed each skill using the human models in skill laboratory. Then, the students performed these skills in Intensive Care Unit. The checklists were completed before training and also 12 days after the end of the training days. The training days were held twice a week and training lasted for 6 weeks.

The intervention group were trained by the same instructor who held a mastery of science. The students' problems in implementing clinical skills were identified and presented as a list to the relevant instructor and student. On the second day, who set special goals for each student based on the problems identified in the first stage. In the intervention group, the instructor used supervisory and observational methods. The instructor re-evaluated the students using the same checklist and re-identified a number of problems that were listed in the checklist daily for 12 days. At the end of the course, the skill scores were checked by the instructor.

\section{Statistical analysis}

Statistical analysis was performed using IBM SPSS Statistics version 21 (Armonk, NY, USA). Data were presented as mean \pm SD and percentage (\%), when possible. After approving the normality of data, independent sample $t$ test was used to compare two groups, and paired t test was used to compare two groups before and after the intervention. $P$ values of less than 0.05 were considered as statistically significant.

\section{Results}

The mean age of participants in the intervention group was $23.3 \pm 1.8$ and in the control group was 23.2 \pm 1.2 . There was no significant difference between two groups in terms of demographic characteristics $(p>0.05)$ (Table1). The results of independent sample $t$ test showed no significant difference between two groups before the intervention in terms of each of ICU procedures $(p>0.05)$. However, paired $t$ test showed that the scores of the intervention group before and after the intervention had a statistically significant difference (Table2). It was also observed that the difference between scores of two groups after the intervention was statistically significant. Moreover, two groups differed significantly regarding the total scores of the students after the intervention (Table3).

\section{Discussion}

In this study, we compared the effect of mastery learning method and common method on skill performance of undergraduate nursing students over three years. The results of this study showed that 
mastery learning method was more effective than common learning method in achieving clinical skills.

One of the most important educational goals of nursing students in each country is the training of skilled professionals with the ability to provide high quality nursing care in the hospitals. Several factors can affect students' clinical education, one of the most important of which is the educational method. The use of new and practical teaching methods in clinical settings can be effective in empowering students. Meanwhile, choosing the type of teaching methodology by instructors is important. The use of mastery learning is considered as a new paradigm in medical education (12).

In Benbassat's study, the effect of mastery learning method on nursing students' physical examination skills was investigated, and it was found that the student's knowledge and skill scores increased (17). Barsuk suggested that the implementation of the mastery learning promoted the general competency of the participants(17). Tang also studies the effect of mastery learning method on clinical training of primary nursing care in nurses. The results showed that nurses' clinical competency increased after implementing this method (18). Contrary to other teaching methods, the instructor knows the problems of the students, and the students know that they have enough time to learn the skills in this method (19). Robert (2013) implemented mastery learning method in nursing education and said: " This method is useful for identification of the professional competence of nursing practice, establishment of criteria for measuring competence, diagnosis of nursing students' learning needs, presentation of a variety of experiences in different situations, repeated assessment at given intervals, clinical activities, and evaluation of nurses' achievement qualifications. However, the main challenges of this educational method is being time-consuming due to need for organization of various tests and high volume of nursing education contents (20).

Additionally, Hasril assessed the effects of mastery learning strategy on knowledge acquisition and concluded that mastery learning strategies, compared to common learning methods, could significantly increase learning in vocational training. He also observed that trainees who received faster feedbacks were more successful in education. Although this method required a lot of time, it reduced time to gain mastery(21).

In this study, we found that mastery learning method was more beneficial than common learning method for educating undergraduate students. Since feedback is provided during teaching process in this method, students can gain the skills with high quality. According to experiences of researcher's team, some students have anxiety then they receive the feedback. Scientific and psychological support of the students can improve their clinical skills. implementing this method and psychological supports the students are important in achieving positive outcomes. But the implementation in higher sample sizes in other nursing students in educational institutions causes further development of this method.

Limitations of study: In this study, the individual in interest and attitude towards the educational methods were not completely controlled by the researcher; however, they were considered in the analysis. Given that sampling was done merely from nursing department in Kerman university of Medical Science, the generalizability of the findings should be done with cautious. 
Finally, investigating the effect of mastery learning method on self-esteem, satisfaction, and competency of undergraduate nursing student is suggested.

\section{Conclusions}

The results of this study showed that the implementation of mastery learning method for clinical skills training could be very effective in improving the quality of clinical learning among undergraduate nursing students. We also found that this method was flexible and could be easily used to improve the students' learning.

\section{Declarations}

\section{Conflicts of interest}

The authors declare that they have no conflicts of interest.

\section{Funding}

This study was financially supported by Kerman University of Medical Sciences, Iran. Number of grant was 930241.

\section{Ethical statement}

The approval for this study was obtained from Ethics Committee of Kerman University of Medical Sciences (IR KMUREC930241). A written informed consent was obtained from each participant. This study was performed on the fourth-year nursing students during fall and spring semesters 2016, 2017 and 2018. Two training methods were performed in intensive care unit in Afzalipour hospital.

\section{Acknowledgement}

We are grateful to the very conscientious referee for his/her constructive comments and suggestions.

\section{References}

1. Ironside PM, McNelis AM, Ebright P. Clinical education in nursing: Rethinking learning in practice settings. Nursing Outlook. 2014;62(3):185-91.

2. Oermann MH, Shellenbarger T, Gaberson K. Clinical teaching strategies in nursing: Springer Publishing Company; 2017.

3. Alzayyat A, Al-Gamal E. A review of the literature regarding stress among nursing students during their clinical education. International Nursing Review. 2014;61(3):406-15.

4. Esmaeili M, Cheraghi MA, Salsali M, Ghiyasvandian S. Nursing students' expectations regarding effective clinical education: a qualitative study. International journal of nursing practice. 2014;20(5):460-7. 
5. Gaberson K, Oermann M. Clinical teaching strategies in nursing: Springer publishing company; 2010.

6. Baraz Pordanjani S, Fereidooni Moghadam M, Loorizade M. Clinical education status according to the nursing and midwifery students' point of view, Tehran university of medical sciences. Strides in Development of Medical Education. 2009;5(2):102-12.

7. Papathanasiou IV, Tsaras K, Sarafis P. Views and perceptions of nursing students on their clinical learning environment: Teaching and learning. Nurse education today. 2014;34(1):57-60.

8. Blomberg K, Bisholt B, Kullén Engström A, Ohlsson U, Sundler Johansson A, Gustafsson M. Swedish nursing students' experience of stress during clinical practice in relation to clinical setting characteristics and the organisation of the clinical education. Journal of clinical nursing. 2014;23(1516):2264-71.

9. Bjørk IT, Berntsen K, Brynildsen G, Hestetun M. Nursing students' perceptions of their clinical learning environment in placements outside traditional hospital settings. Journal of clinical nursing. 2014;23(19-20):2958-67.

10. Tafazzoli M, Fakari FR, Ramazanzadeh M, Sarli A. The relationship between critical thinking dispositions and academic achievement in Iranian midwifery students. Nursing Practice Today. 2016;2(3):88-93.

11. Tanaka M, Taketomi K, Yonemitsu Y, Kawamoto R. Professional behaviours and factors contributing to nursing professionalism among nurse managers. Journal of nursing management. 2016;24(1):1220.

12. McGaghie WC. Mastery learning: it is time for medical education to join the 21 st century. Academic Medicine. 2015;90(11):1438-41.

13. Griswold-Theodorson S, Ponnuru S, Dong C, Szyld D, Reed T, McGaghie WC. Beyond the simulation laboratory: a realist synthesis review of clinical outcomes of simulation-based mastery learning. Academic Medicine. 2015;90(11):1553-60.

14. Devine LA, Donkers J, Brydges R, Perelman V, Cavalcanti RB, Issenberg SB. An equivalence trial comparing instructor-regulated with directed self-regulated mastery learning of advanced cardiac life support skills. Simulation in healthcare. 2015;10(4):202-9.

15. McGaghie WC, Issenberg SB, Barsuk JH, Wayne DB. A critical review of simulation-based mastery learning with translational outcomes. Medical Education. 2014;48(4):375-85.

16. Damavandi ME, Kashani ZS. Effect of mastery learning method on performance, attitude of the weak students in chemistry. Procedia-Social and Behavioral Sciences. 2010;5:1574-9.

17. Barsuk JH, Cohen ER, Wayne DB, Siddall VJ, McGaghie WC. Developing a simulation-based mastery learning curriculum: lessons from 11 years of advanced cardiac life support. Simulation in Healthcare. 2016;11(1):52-9.

18. Tang WE, Dong L. Applying mastery learning in a clinical skills training program for primary care nurses. The Journal of Continuing Education in Nursing. 2013;44(12):535-41.

19. Hattie J. The applicability of Visible Learning to higher education. Scholarship of Teaching and Learning in Psychology. 2015;1(1):79. 
20. Roberts DS, Ingram RR, Flack SA, Hayes RJ. Implementation of mastery learning in nursing education. Journal of Nursing Education. 2013;52(4):234-7.

21. Amiruddin MH, Zainudin FL. The Effects of a Mastery Learning Strategy on Knowledge Acquisition among Aboriginal Students: An Experimental Approach. International Journal of Vocational Education and Training Research. 2015;1(2):22-6.

\section{Tables}

Table1: Demographic characteristics of nursing students

Common learning Mastery learning Demographic characteristics

\begin{tabular}{|l|ll}
\hline $23.2 \pm 1.2$ & $23.3 \pm 1.8$ & age \\
\hline $61.5 \%$ & $62.3 \%$ & Female male \\
$38.5 \%$ & $37.7 \%$ & \multicolumn{1}{c}{ sex } \\
\hline $16 \pm 0.4$ & $15.5 \pm 1.6$ & Scale median \\
\hline $58.4 \%$ & $59.7 \%$ & Interested in nursing: yes \\
$41 / 6 \%$ & $40.3 \%$ & \\
\hline $94.4 \pm 7.3$ & $92.2 \pm 10.2$ & Passed unites \\
\hline $69.2 \%$ & $68.9 \%$ & Native \\
\hline $30 / 8 \%$ & $31.1 \%$ & Non native \\
\hline
\end{tabular}

Table 2: median skills scales in two group 


\begin{tabular}{|c|c|c|c|c|c|c|}
\hline procedurs & Mastery le & arning gro & & nmon learni & g group & \\
\hline Tracheal and & before & after & $\mathrm{p}$ & before & after & $\mathrm{p}$ \\
\hline Suction 19-38 & $27.9 \pm 1.2$ & $35.9 \pm 2.71$ & $0.000^{*}$ & $22.3 \pm 1.2$ & $23.1 \pm 0.5$ & $0.13^{*}$ \\
\hline NGTube feeding & & $36.1 \pm 1.59$ & $0.000^{*}$ & $22.07 \pm 1.2$ & $23.05 \pm 0.2$ & \\
\hline $19-38$ & $25.7 \pm 1.94$ & & & & & $0.24 *$ \\
\hline Pack cell Transfusion 13-26 & $19.1 \pm 3.2$ & $22 \pm 1.7$ & $0.01 *$ & $17.3 \pm 0.2$ & $17.5 \pm 0.02$ & $0.14^{*}$ \\
\hline Changing set and fluid box & $22.3 \pm 0.2$ & $38 / 5 \pm 1.3$ & $0.01 *$ & $24.3 \pm 1.2$ & $25.7 \pm 0.12$ & $0.13^{*}$ \\
\hline $21-42$ & & & & & & \\
\hline Change fluid box & $10.2 \pm 1.7$ & $14.3 \pm 2.3$ & $0.001 *$ & $10.8 \pm 1.5$ & $11.2 \pm 0.14$ & $0.28 *$ \\
\hline $8-16$ & & & & & & \\
\hline
\end{tabular}

*Paired t test

Table3:Compare Practice scales between two groups

\begin{tabular}{l|lll} 
GROUP & TOTAL & & \\
\hline MASTERY LEARNING GROUP & before & after & \\
\cline { 2 - 3 } COMMON LEARNING GROUP & $21.04 \pm 1.64$ & $29.36 \pm 1.9$ & \\
\cline { 3 - 4 } & $19.35 \pm 1.06$ & $20.11 \pm 0.19$ & \\
& & & \\
\end{tabular}

*independent sample $\mathrm{t}$ test 